\title{
MEMÓRIA: \\ Construção Social, Lugares e Competência
}

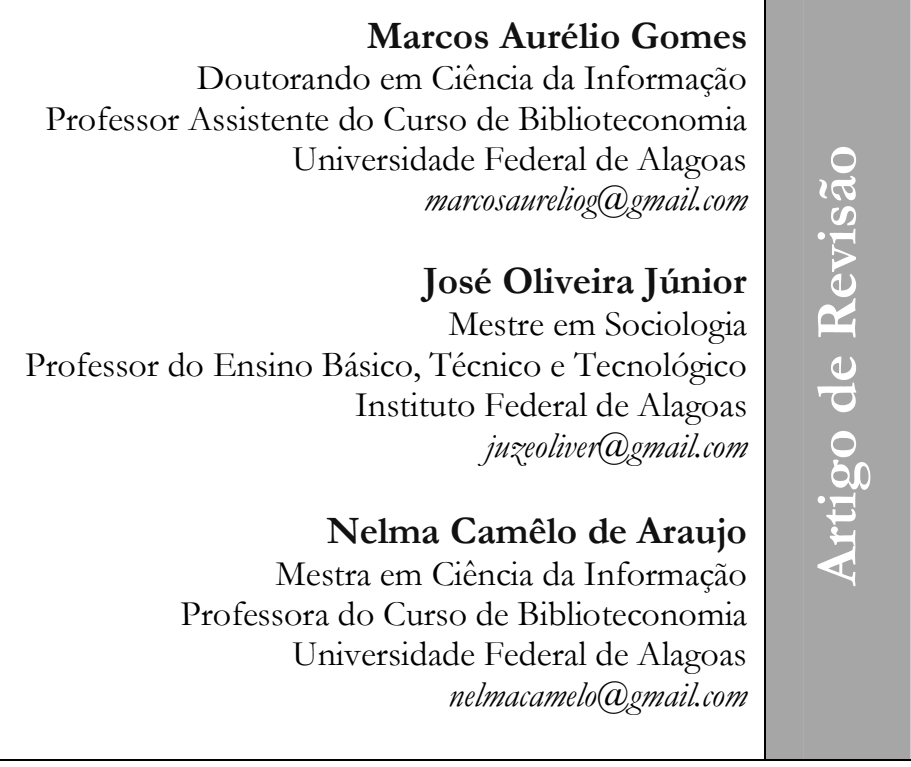

\section{Resumo}

Partindo do princípio de que a informação registrada serve como insumo à produção de bens materiais simbólicos e de novos conhecimentos, o tema memória torna-se recorrente em diversas áreas do conhecimento científico, estabelecendo nexos entre sujeitos do passado e a sociedade contemporânea. Nesse sentido, buscaram-se considerações acerca da temática memória que pudessem relacionar-se com a tricotomia: indivíduo, lugares e competências. Para essa abordagem se fizeram necessárias definições e pesquisas em áreas correlatas, assim este trabalho é fruto de reflexões advindas das áreas da Ciência da Informação e Ciências Sociais, abordando-se essencialmente alguns autores consagrados nesta temática: memória. Espera-se que os argumentos expostos possam colaborar com a construção de novos conhecimentos que abarquem o aprofundamento de estudos sobre os sistemas memoriais.

\section{Palavras-chave}

Memória social. Competência informacional. Lugar de memória. Sistema memorial.

\section{INTRODUÇÃO}

O entendimento de que a informação tornou-se essencial para possíveis ações e decisões com maior propriedade quer no âmbito individual e/ou coletivo e nos mais variados contextos tornou-se, de certa forma, senso comum.

Por outro lado, é inegável que a contemporaneidade trouxe novas formas de produção e consumo advindas por meio das inovações tecnológicas e organizacionais, globalização da economia, padrões de qualidade, entre outras. Nesse cenário, mudanças paradigmáticas foram engendradas provocando alterações significativas e que são percebidas no modus operandi da sociedade. Ancoradas nessas mudanças, as instituições e organizações exercem influências sobre os arquivos, bibliotecas e museus, estes muitas vezes moldados e dependentes das estruturas social, política e econômica vigentes em determinadas sociedades.

Shera (1972, p. 135, tradução nossa) por sua vez alertava que "[...] a sociedade determinou o que foi a biblioteca do passado, e 
é a sociedade que irá determinar o que será a biblioteca do futuro [...]", e no lastro desta compreensão incluem-se os arquivos e museus. Contudo a sociedade tem a percepção de para que servem essas instituições/organizações sociais? Há o entendimento de que eles são depositários da memória e possibilitam a preservação e o acesso à informação? Que lugares de memórias podem ser amplos e variados? Que a prática da leitura é fator considerável ao não esquecimento? Que se pode aprender e "aprender a aprender" por meio da informação?

$\mathrm{Na}$ tentativa do entendimento dessas questões é que se buscou referencial teórico como suporte necessário para o desenvolvimento deste trabalho. Entretanto, não é a intenção dos autores realizar um trabalho exaustivo sobre a temática e nem tampouco inovador, mas trazer para a reflexão conceitos e abordagens úteis para a área e, dessa forma, possibilitar novos questionamentos e suscitar outras pesquisas.

Nesse sentindo, parte-se da constatação da possibilidade de que a informação registrada sirva como insumo à produção de bens materiais simbólicos e de novos conhecimentos, como instrumento de apoio à decisão, como suporte para a defesa de interesses, como material informacional para $\mathrm{o}$ ensino e a aprendizagem.

Infere-se que a partir da assimilação da informação $\mathrm{O}$ indivíduo possa garantir $\mathrm{O}$ exercício de sua condição de cidadão. Considera-se então que o direito à informação é a síntese dos direitos sociais. $\mathrm{O}$ direito de se comunicar engloba, assim, o direito de participar, de se informar, de receber e de ter acesso à informação (MARINHO JUNIOR; GUIMARÃES e SILVA, 1998).

\section{MEMÓRIA: UMA CONSTRUÇÃO SIMBÓLICA E SOCIAL}

Com o avanço das pesquisas científicas a partir do século XVIII, os estudos sobre comportamento, personalidade, sociedade e cultura tomam novas dimensões e contornos.

A psicologia como ciência tem um crescimento profundo em diversas questões de cunho psíquico e social. Desse modo, a partir do século XIX os estudos de Henri Bergson (1859-1941), com sua obra Matière et Mémoire (Matéria e Memória), publicada em 1897, abre precedentes para a pesquisa sobre memória. Em seu início esses estudos estavam ligados diretamente à disciplina e ciência psicológica, posteriormente o sociólogo Maurice Halbwachs (1877-1945) desenvolveu o primeiro trabalho de cunho sociológico tendo a memória coletiva como categoria.

A memória é a responsável por esta relação entre corpo presente e passado, interferindo no processo das representações atuais. Através da memória o passado vem à tona, misturado de fatos e eventos presentes.

A sociologia proposta por Halbwachs ${ }^{1}$, discípulo de Émile Durkheim, aproxima-se da realidade concreta da existência a partir da análise dos quadros sociais da memória, indo do longínquo ao próximo, sendo seu trabalho influenciado e inspirado na obra "Formas Elementares da Vida Religiosa" (1912) de Durkheim. Prolonga os estudos durkheimianos que seguiram a pesquisa de campo nas hipóteses de Auguste Comte, no que diz respeito à precedência do fato social e do sistema social sobre fenômenos de ordem psicológica e individual. Conforme Bosi (1994, p. 53), "Com Durkheim, o eixo das investigações sobre a 'psique' e o 'espírito' se desloca para as funções que as representações e idéias dos homens exercem no interior do seu grupo e da sociedade em geral".

É por isso que Halbwachs dará um tratamento da memória como um fenômeno social e refinará em vários momentos a definição de seu mestre. Estudará a memória como sendo quadros sociais. Dirá que é impossível conceber o problema da evocação, assim como o da localização das lembranças, se não pegarmos como ponto de aplicação os quadros sociais reais que servirão de referência nesta reconstrução que chamará de memória.

Para esse autor a capacidade de lembrar é radical porque não se trata apenas de um condicionamento externo de algo que é interno, ou seja, não é uma justaposição de quadros sociais e imagens evocadas. Entende-

1 Maiores embasamentos por meio das seguintes obras de Halbawachs: "Os quadros sociais da memória" (1925) e “A memória coletiva” (1950). 
se que dentro do interior da lembrança são trabalhadas noções gerais transmitidas através da linguagem, conhecimento, filiação institucional. Devido ao caráter objetivo, transubjetivo, essas noções gerais, essas imagens, resistem e são transformadas em lembranças. Por isso, Bosi (1994, p. 63) nos alerta para "[...] a coerência do pensamento de Halbwachs: o que rege, em última instância, a atividade mnêmica é a função social exercida aqui e agora pelo sujeito que lembra." Quem lembra, para Halbwachs, recorda a vida em sociedade.

O ser humano ativo preocupa-se menos em lembrar porque, para ele, a vida é prática, e dessa maneira a memória seria uma fuga, arte, lazer, contemplação. Na memória fica aquilo que significa, mas fica não do mesmo jeito, intacto, às vezes o que fica é profundamente alterado. Isso porque novos significados alteram o conteúdo e o valor da situação evocada (BOSI, 1994).

Com Halbwachs passamos a pensar na memória como uma construção social e cultural. Para Bosi (1994), no momento no qual uma classe social trabalha em conjunto veementemente existe uma tendência de criar esquemas mais ou menos coerentes de narração e interpretação dos eventos. Os eventos testemunhados têm uma forma histórica própria, ao contrário dos que não foram testemunhados, que se perdem no caminho.

Memórias são influenciadas pela organização social e cultural de transmissão e seus diversos meios de comunicação empregados. Para que serve a memória social? Esta é uma questão bastante ampla e controversa, pois o exemplo que se tem a respeito do uso da memória social nos conduz sempre a imagens de governantes como heróis populares. Por isso, Burk (2006, p. 81) diz que "Nas histórias, os desastres acompanham a morte ou desaparecimento do herói." Outra maneira, de acordo com Burk (2006), de abordar os usos da memória social é questionar o porquê de algumas culturas se preocuparem mais em lembrar do que outras o seu passado.

O longo silêncio sobre o passado não conduz ao esquecimento, pelo contrário, impõe uma resistência e um excesso de discurso oficial. As lembranças são transmitidas pela família, associações, redes de sociabilidade afetiva e política. Dessa maneira, segundo Pollak (1998, p. 08), "[...] existem nas lembranças de uns e de outros zonas de sombra, silêncios, "não-ditos"'. Existe uma interação permanente entre o vivido e o aprendido. E essas constatações se aplicam a toda forma de memória. Por isso, a história de vida ordena os eventos que marcam uma existência porque mesmo o nível de trabalho individual da memória é indissociável da organização social da vida.

O tempo da memória é social e cultural. $\mathrm{O}$ indivíduo lembra o que o grupo transmite e aquilo que vive e signifique. Tempo e espaço existem nas lembranças. No entanto, estamos vivendo e sentindo o desencaixe desse espaço e tempo. Por isso, para Eckert e Rocha (2001, p. 31), “[...] a matéria do tempo traduz em raios ondulatórios lembranças e reminiscências cujos feixes de ondas se transformam reciprocamente em matéria." $\mathrm{O}$ concreto habita a memória porque está na lembrança vivida e sentida.

Reviver o tempo que passou é aprender e perceber o que foi e como tem sido. A memória é um fragmento do evento e cotidianidade do que passou. Por isso, o sentido das identidades consiste nos arranjos e rearranjos dos pedaços e fragmentos do passado.

A memória dirige a vida de cada um de nós. A importância da memória coletiva no que diz respeito ao ato individual de lembrar é tão poderosa, que os fatos e noções mais fáceis de lembrar são os de domínio comum.

Nos dias atuais cada vez mais é pensada a relação entre história e memória, porque a história tida como oficial afasta os aspectos que são inerentes ao cotidiano e aos comportamentos dos sujeitos. A tradição oral é um instrumento de grande valia quando desejamos constituir a crônica do cotidiano.

A cidade não é somente um conjunto de representações, lembrança inscrita no espaço, no corpo e na mente, é feita de lembranças que suscitam e estimulam a memória e permitem localizar as lembranças nos aspectos temporais, espaciais e relacionais. 
Isso passa a acontecer porque é um lugar. Assim para

Recuperar o passado individual e coletivo, por meio da memória como metodologia de análise, configura-se como um dos caminhos possíveis para a descoberta dos processos de desenraizamento social e cultural e, por conseguinte, para a redefinição dos projetos que articula passado, presente e futuro. (SILVA, 2007, p. 295)

Com isso, poderemos perceber a memória como uma construção social e espacial dos sujeitos que residem em um espaço habitado. A memória se fecha e se abre, porque estamos em contato com diversas culturas, etnias, espaços, movimentos políticos que nos fazem refletir acerca do nosso meio na interação com o todo. Habitamos e somos habitados. Logo, se percebe quais seriam as atuações de arquivos, bibliotecas e museus nesses locais sociais.

\section{LUGARES DE MEMÓRIA}

O tema memória vem ganhando notoriedade atualmente, uma vez que o mundo está cada vez mais rápido, principalmente pelo uso das novas tecnologias de informação e comunicação, como explicita Oliveira e Rodrigues:

As limitações da memória humana levaram o homem a buscar em recursos externos, as chamadas memórias artificiais, a compensação para o esquecimento. A necessidade de possibilitar o acesso aos registros por ele produzidos ao decorrer do tempo levou à criação das chamadas instituições de memória que deveriam preservar os registros do conhecimento humano nas suas mais diversas formas de materialização [...] (OLIVEIRA; RODRIGUES, 2012, p.495).

Diante do exposto acima, acrescenta-se que as pessoas e as instituições já não conseguem mais planejar suas vidas vislumbrando um futuro longínquo. As guerras e as tragédias da natureza destroem não apenas os bens materiais, mas também levam consigo pessoas e seus bens mais íntimos, fotografias, documentos de família, documentos pessoais e aqueles relacionados à vida profissional do indivíduo. Sendo assim torna-se premente o registro e conservação sobre a passagem do homem ao longo de sua existência.

Ao tratar o assunto memória, Le Goff (2003) destaca que foram os gregos antigos que fizeram da Memória uma deusa, de nome Mnemosine. Ainda segundo o autor, a memória coletiva faz parte das grandes questões das sociedades desenvolvidas e das sociedades em vias de desenvolvimento, das classes dominantes e das classes dominadas, lutando todas pelo poder ou pela vida, pela sobrevivência e pela promoção.

A memória se constitui em um dos elementos de pesquisa, visto que a necessidade de preservação da memória e a disseminação da experiência coletiva na sociedade visam garantir a perenidade do patrimônio documental para permitir que gerações futuras conheçam o passado. Nessa direção,

[...] a memória está em voga, e não só como tema de estudo entre especialistas. Também a memória como suporte dos processos de identidade e reivindicações respectivas está na ordem do dia [...] Todos têm procurado destilar sua auto-imagem - mais raramente e com dificuldade e a da sociedade como um todo. Palavras-chave são "resgate", "recuperação" e "preservação" todas pressupondo uma essência frágil que necessita cuidados especiais para não se deteriorar ou perder uma substância preexistente. A comunicação de massa e o mercado (antiquariato, moda) reforçam essa reificação. (MENESES, 2006, p.12).

A multiplicidade de memórias presentes na vida da sociedade pode ser explorada sob a ótica da representação que o "lembrar" apresenta ao indivíduo.

Assim, os atributos da memória individual necessitam ter respaldo no coletivo, ou seja, não se constrói uma memória tendo 
apenas um interlocutor para os fatos, se faz necessário que cada informação repassada individualmente seja apresentada a outras pessoas, com o objetivo de validar e/ou acrescentar outras informações. E mais, é preciso que os registros comprovem as "lembranças" individuais ou coletivas, não ficando apenas essas "lembranças" como um produto da criatividade individual. Dessa forma,

[...] e, assim entendido, o conceito de memória, em toda a sua complexidade, é também uma faculdade do espírito, base de toda a criação. E, como tal, é uma invenção do ser humano. Isso significa abolir as definições que fazem da memória mera repetição de acontecimentos passados. Nesse sentido, as informações retidas, que passaram por um filtro individual (que é também social) são organizadas e recriadas no presente, dentro de um processo dinâmico. (COSTA, 1997, p. 129)

Oliveira (2010), ao pesquisar em sua tese a produção científica sobre o tema memória na Ciência da Informação, usando as fontes da área, sendo as mesmas: Library Information Science Abstract (LISA), artigos dos periódicos especializados da área, anais dos encontros nacionais de Pesquisa em Ciência da Informação (ENANCIB) e teses e dissertações produzidas nos programas de pós-graduação em Ciência da Informação no Brasil, no período de 1972 a 2005, identificou que os trabalhos produzidos no Brasil na sua maioria "[...] relacionam memória a informação, considerando especialmente as informações registradas (documentos), nos mais variados suportes, como elementos de relevância para a memória social, em vários níveis: local, regional ou nacional." (OLIVEIRA, 2010, p.112).

A conservação e preservação dessa memória estão relacionadas às instituições que oferecem a guarda, processamento, organização, acesso e disseminação do patrimônio cultural da sociedade, sendo as mesmas no nosso entendimento como profissionais da informação: bibliotecas, arquivos e museus.

Para Gomes (2007) as "instituições memoriais" são evidências dos espaços de acesso aos registros da memória de uma sociedade, sejam essas instituições públicas ou privadas.

As bibliotecas representam uma diversidade de saberes muito importante, pois suas características estão relacionadas à próximidade que as mesmas têm com seus usuários, sendo divididas em bibliotecas públicas, escolares, universitárias e especializadas. Independente de suas funções e de seu suporte, a biblioteca é um grande repositório de acervos, retratando a cultura da comunidade na qual ela está inserida, seja ela empresarial, social ou econômica, preservando assim a memória dessa comunidade.

A biblioteca refere-se a uma grande variedade de coleções bibliográficas e aos diferentes fins e usuários. A maioria das nações desenvolvidas dispõe de bibliotecas de vários tipos: nacionais, universitárias, públicas, escolares e especializadas. Esses tipos de bibliotecas sempre estão interligados, por meio de associações profissionais e de acordos estabelecidos em que desenvolvem programas de cooperação e intercâmbio extensivos a outros países (GALDINO et al., 2011, p.7).

A própria história da biblioteca vem ao encontro da necessidade de se preservar a memória da humanidade. Temos o modelo da primeira biblioteca mundial, a de Alexandria, que mantinha em seu acervo registro das publicações dos grandes filósofos da época e também a história do desenvolvimento da sociedade.

Já os arquivos preservam os documentos que são produzidos por uma entidade pública ou privada, no transcurso das funções que justificam sua existência, e, como tal, guardam esses documentos relações orgânicas entre si. Surgem, pois, por razões funcionais administrativas e legais. Sua apresentação pode ser manuscrita, impressa ou audiovisual; via de regra, exemplares únicos e com forma e suporte variados, desde que auxiliem no cumprimento da missão maior das instituições. 
A abordagem sobre o que ocorre ao longo da trajetória de uma instituição fica normalmente registrada apenas nos documentos formais, subsidiando a legislação sobre as práticas da organização. Entretanto, muitas informações importantes são de conhecimento individual ou coletivo, constituindo-se nos recursos intangíveis de toda instituição, pública ou privada.

Para Barros e Neves (2009, p.2) "O arquivo é visto aqui como um lugar em que a memória se torna participante do processo de identidade, como praxe e representação da sociedade da informação[.]”. Os autores defendem que o arquivo é o registro das informações da sociedade ao longo do tempo na história, tendo como função manter viva essa memória.

Os historiadores sempre consideraram o arquivo como a principal fonte de informações para suas pesquisas, pois essa "instituição memorial" armazena a produção administrativa, legal e de identidade de época de um país.

Os museus são instituições que armazenam bens materiais e imateriais sobre a memória de um povo, constituindo-se patrimônio desse povo. Diversos tipos de museus são formados em cada cidade no mundo. Esses museus têm a preocupação de guardar objetos específicos sobre determinadas ações de pessoas que representaram a cultura da comunidade local, ou acervo sobre as circunstâncias dessa comunidade em determinada época.

Existem museus de história natural, mostrando a evolução do ser humano ao longo de seu desenvolvimento, são estes os museus imateriais. Hoje, no século XXI, alguns museus não permitem a exposição de suas peças ao público, preservando sua materialidade, assim são criados os museus virtuais, sendo às vezes mais detalhados para o pesquisador do que se este estivesse in loco vendo as peças.

Araújo (2010) relaciona as três instituições como aquelas que sempre existiram para a preservação da cultura da humanidade.

Bibliotecas, arquivos e museus são instituições cuja origem se confunde com a própria idéia de cultura. Desde as sociedades da Antiguidade, existe a preocupação com a preservação e transmissão das experiências e conhecimentos acumulados, implicando algum tipo de inscrição material destas experiências e conhecimentos. A origem das bibliotecas e arquivos é comumente relacionada à origem da passagem da oralidade para a escrita; a dos museus, associada ao colecionismo que marcou as grandes civilizações da Antiguidade. (ARAÚJO, 2010, p.177)

Se preservarmos a cultura, preservamos a memória registrada em qualquer suporte de informação, e como "instituições memoriais" as bibliotecas, os arquivos e museus têm a função não apenas da guarda dessa memória, mas também de proporcionar o acesso a esse acervo.

\section{LUGARES DE MEMÓRIA E POSSÍVEIS RELAÇÕES COM AS COMPETÊNCIAS EM INFORMAÇÃO}

Diante do exposto, ao reforçar-se o debate que considera as bibliotecas, arquivos e museus como espaços ou locais de memória, Nora (1993, p. 15, grifo nosso) enfatiza que a memória é "[...] a constituição [...] do estoque material daquilo que nos é impossível lembrar, repertório [...] daquilo que poderíamos ter necessidade de nos lembrar." Assim, uma articulação polissêmica que se apresenta entre informação e memória (DODEBEI, 2010). Dessa forma, o estoque e o repertório se configurariam como um possível dispositivo de ativação da memória para alguns, na medida em que esse estoque (textos, imagens, sons) esteja representado para que possa ser acessado, isto é, por indivíduos que possuam habilidades informacionais.

Murguia (2010), ao dialogar com Nora (1993) sobre lugares de memória, alerta para possíveis debates que se abrem para os campos da Arquivologia, Biblioteconomia e Museologia; assim, seria "[...] um campo fértil para rediscutir-se, quando não para redefinirse.” (MURGUIA, 2010, p. 27). Possivelmente, o movimento da competência em informação se enquadraria nestas novas discussões, pois a biblioteca se tornaria sobre essa ótica um local 
de aprendizagem por meio da informação, e isso poderia se estender também aos arquivos e museus. Campello (2008) reforça essa proposição ao afirmar que, por meio de sua prática pedagógica, a biblioteca poderá ser um instrumento auxiliar no desenvolvimento dos indivíduos frente aos novos desafios postos pelo novo século.

Nessa perspectiva, bibliotecas como também arquivos e museus integram um sistema memorial (LIMA, MIRANDA, VILDEANE，2011; GOUVEIA JUNIOR, LIMA, 2012), um conjunto articulado, integrado e complexo para satisfazerem, entre outros objetivos, as necessidades de informação dos indivíduos.

Para Gouveia Junior e Lima (2012), o campo da Ciência da Informação percebe a memória como ações para preservar e disseminar a informação, em outras palavras, são abordagens que medeiam a produção, seleção, organização e uso da informação e em contextos diversos.

Essas discussões não acontecem isoladas, pelo contrário, representam o momento histórico-social no qual se inserem os sujeitos e as instituições. Assim, acumular, preservar, armazenar e disponibilizar acesso à informação é olhar para a interlocução entre os diversos atores sociais, possíveis necessidades de informação e os múltiplos espaços nos quais o fluxo da informação pode ser determinante para os desdobramentos nos campos político, econômico, cultural e educacional na sociedade.

Kumar (1997, p. 15) apresenta a sociedade da informação como uma "nova sociedade", como sendo aquela que é "[...] definida e rotulada por seus novos métodos de acessar, processar e distribuir informação." Nessa "nova" sociedade, a "[...] competência informacional foi a bandeira erguida pela classe bibliotecária americana [...] para as mudanças demandadas pela sociedade da informação." (CAMPELLO, 2003, p. 32).

A partir daí, potencializam-se as questões relacionadas à necessidade, localização, acesso/recuperação, uso e comunicação da informação em diversos espaços sociais, pois essa competência pretende possibilitar o aprender a aprender por meio da informação, seja em ambiente tradicional ou digital. Lastres e Ferraz (1999) alertam que esse tipo de competência ${ }^{2}$ é fundamental devido ao excesso de informação existente, ou, como eles denominam, a "hiperinformação".

Compreende-se então que a existência de arquivos, bibliotecas e museus pode ser relevante para provocar possíveis rupturas, isto é, provocar novas relações sociais entre esses espaços e os indivíduos (MURGUIA, 2010).

A noção de competência em informação começa ser delineada nos anos de 1970, nos Estados Unidos, como uma estratégia para que os indivíduos desenvolvessem habilidades para o acesso e uso efetivo e eficaz do acúmulo de informação disponível e dos diversos dispositivos tecnológicos que começam a surgir (CAMPELLO, 2003; DUDZIAK, 2003; GASQUE, 2010; SIQUEIRA, 2011).

Para Morigi et al. (2012, online) a competência relacionada à informação se traduz no entendimento do "[...] aprendizado necessário para lidar com o volume de informação disponível em todas as áreas do conhecimento [...]", e possivelmente nos mais diversificados espaços, dos tradicionais aos híbridos e virtuais.

Assim, a competência em informação comporta o domínio consciente e atitudinal do indivíduo, no qual estão envolvidos elementos cognitivos, físicos, operacionais e éticos relacionados à informação (BELLUZZO, 2010; DUDZIAK，2003; HATSCHBACH; OLINTO, 2008).

Le Coadic (2004, p. 114) acredita que há necessidade de uma educação para a informação, pois os indivíduos precisam ao mesmo tempo "aprender a se informar e aprender a informar, e sobre onde adquiri-las". Logo, envolve um processo relacionado da busca à comunicação da informação e articulado com as necessidades de informação.

\footnotetext{
2 Esses autores não utilizam literalmente os termos "competências em informação" ou "competência informacional", entretanto, evidencia-se que, quando esses autores discutem as questões relacionadas à informação, conhecimento e aprendizado, se referem a competência ou habilidade (inter)relacionada à informação.
} 
Nesse contexto, localizam-se as economias que são marcadas pela competitividade quer entre si, organizações e indivíduos e, por conseguinte, a competência em informação se inscreve em ambientes diversos e, principalmente, naqueles intensivos em informação na qual a mesma torna-se insumo para a tomada de decisões.

Ainda, vale ressaltar Lastres e Ferraz (1999, p. 50) quando discutem a reestruturação das atividades econômicas, nas quais a informação torna-se componente diferenciador para as organizações e a necessidade do aprendizado. Assim, esses autores afirmam que "[...] mais grave do que não possuir fontes de acesso a informação, seja não dispor de capacidade de aprendizado e conhecimentos suficientes para fazer uso das mesmas.".

A despeito de quaisquer ideologias, a competência em informação torna-se necessária em contextos diversos para mobilizar os recursos informacionais disponíveis e alcançar vantagens competitivas impostas pelo capitalismo.

Para além dessas questões, a competência em informação possibilita um amplo debate e/ou um campo de estudos que envolveria as políticas relacionadas à informação (fontes, espaços, práticas, agendas de pesquisa, entre outras). Arquivos, bibliotecas e museus integram-se nessas políticas, pois são entendidos como sistemas transmissores de informação e conhecimento.

\section{CONCLUSÃO}

A memória, desde a Antiguidade até os dias, atuais reflete questões das sociedades em perspectivas múltiplas, seja de sua cultura, social ou econômica, podendo inclusive ser um diferencial de seu desenvolvimento.

$\mathrm{Na}$ sociedade, ao invés de os sujeitos se uniformizarem, pelo contrário, eles se diferenciam. Ninguém pode lembrar-se efetivamente senão por meio da presença ou a evocação dos indivíduos ou de seus registros, isso porque um ser humano que lembra sozinho não representa a memória coletiva, sendo necessário o registro, sendo este o instrumento para acesso à memória.

Como armazenadores de memória no Brasil, as bibliotecas, arquivos e museus ainda não exercem um papel proativo na disseminação de seus conteúdos para a sociedade na qual estão inseridos, talvez por não disporem exatamente dos recursos necessários frente aos diversos desafios sociais, econômicos e políticos que, muitas vezes, não priorizam tais equipamentos.

Reforça-se, assim, a necessidade de uma agenda de pesquisa para se discutir as competências em informação relativas ao acesso e uso dos registros de memória em quaisquer ambientes múltiplos e diversos.

\title{
MEMORY: Social Construction, Place and Literacy
}

\begin{abstract}
Assuming that the recorded information serves as an input to the production of material and symbolic of new knowledge, the memory becomes theme recurring in various areas of scientific knowledge, it establishes links between subjects of the past with contemporary society. In this sense, sought to considerations about the theme memory that could relate to the trichotomy: individual, places and skills. For this approach was necessary definitions and research in related areas, so this work is the result of reflections coming from the areas of Information Science and Social Sciences, focusing mainly some established authors in this subject: memory. Thus it is expected that the arguments can collaborate with the construction of new knowledge that cover further studies on systems memorials.
\end{abstract}

Keywords

Social memory. Information literacy. Place of memory. Memorial system.

Artigo recebido em 12/07/2014 e aceito para publicação em 29/09/2014 


\section{REFERÊNCIAS}

ARAÚJO, C. A. A. Ciência da Informação como campo integrador para as áreas de biblioteconomia, arquivologia e museologia. Informação \& Informação, Londrina, v. 15, n. 1, p. 173 - 189, jul./jun. 2010.

BARROS, D. S. ; NEVES, D. A. de B. Arquivo e memória: uma relação indissociável. TransInformação, Campinas, v. 21, n.1, p.5561, jan./abr., 2009.

BELLUZZO, R. C. B. Competências e novas condutas de gestão: diferenciais de bibliotecas e sistemas de informação. In: VALENTIM, M. L. P. (Org.). Ambientes e fluxos de informação. São Paulo: Cultura Acadêmica, 2010. p. 23-54.

BERGSON, H. Cartas, conferências e outros escritos. São Paulo: Abril Cultural, 1979.

BOSI, E. Memória e Sociedade: Lembranças de velhos. 3. ed. São Paulo: Companhia das Letras, 1994.

BURK, P. Variedades de história cultural. 2. ed. Rio de Janeiro: Civilização Brasileira, 2006.

CAMPELLO, B. S. A competência informacional na educação para o século XXI. In:__et. al. A biblioteca escolar: temas para uma prática pedagógica. 2. ed. Belo Horizonte: Autêntica, 2008. p. 9-11.

O movimento da competência informacional: uma perspectiva para o letramento informacional. Ciência da Informação, Brasília, v. 32, n. 3, p. 28-37, set./dez. 2003.

COSTA, I. T. M. Memória institucional: a construção conceitual numa abordagem teórico-metodológica. 166 f. 1997. Tese (Doutorado em Ciência da Informação) Universidade Federal do Rio de Janeiro, 1997. Disponível em: < http://tede-
dep.ibict.br/tde_busca/arquivo.php?codArqui vo $=24>$. Acesso em: 20 jul. 2013.

DODEBEI, V. Memória e informação interações no campo da pesquisa. In:

MURGUIA, E. I. (Orgs.). Memória: um lugar de diálogo para arquivos, biblioteca e museus. São Carlos: Compacta Gráfica e Editora. 2010. p. $59-78$.

DUDZIAK, E. A. Information literacy: princípios, filosofia e prática Ciência da Informação, Brasília, v. 32, n. 1, p. 23-35, jan./abr. 2003.

ECKERT, C.; ROCHA, A. L. C. da. Imagens do tempo nos meandros da memória : por uma etnografia da duração. In: KOURY, M. G. P. (Org). Imagem e Memória, ensaios em Antropologia visual. Rio de Janeiro: Garamond, 2001.

GALDINO, R. Z. et al. História da Ciência da Informação e da biblioteca: a memória da escrita e da biblioteca. Disponível em: $<$ http://rabci.org/rabci/sites/default/files/HI ST $\%$ C3\%93RIA $\% 20 \mathrm{DA} \% 20 \mathrm{CI} \% \mathrm{C} 3 \% 8 \mathrm{ANCI}$ A $\% 20$ DA $\% 20$ INFORMA $\%$ C3\%87\%C3\%83 O $\% 20 \mathrm{E} \% 20 \mathrm{DA} \% 20 \mathrm{BIBLIOTECA} \% 20 \mathrm{~A} \% 20$ Mem $\%$ C3\%B3ria $\% 20 \mathrm{da} \% 20$ Escrita $\% 20 \mathrm{e} \% 20$ da $\% 20$ Biblioteca.pdf $>$ Acesso em: 22 jul. 2013.

GASQUE, K. C. G. D. Arcabouço conceitual do letramento informacional. Ciência da Informação, Brasília, v. 39, n. 3, p.83-92, set./dez. 2010.

GOMES, A. M. de C. Justiça do trabalho no Brasil: notas de uma pesquisa. In: BIAVASCHI, M. B.; LUBBE, A.; MIRANDA, M. G. (Coord.). Memória e preservação de documentos: direitos do cidadão. São Paulo: LTr, 2007. p. 19-31.

GOUVEIA JUNIOR, M.; GALINDO, M. Sistemas memoriais como disseminadores de informação. TransInformação, Campinas, v.24, n.3, p. 207-217, set./dez., 2012. 
HALBWACHS, M. A memória coletiva. São Paulo: Vértice, 1990.

HATSCHBACH, M. H. de L.; OLINTO, G. Competência em informação: caminhos percorridos e novas trilhas. Revista Brasileira de Biblioteconomia e Documentação, Nova Série, São Paulo, v.4, n.1, p. 20-34, jan./jun. 2008. Disponível em: $<$ http://rbbd.febab.org.br/rbbd/article/view/ 64>. Acesso em: 10 maio 2013.

KUMAR, K. Da sociedade pós-industrial à pós-moderna: novas teorias sobre o mundo contemporâneo. Rio de Janeiro: Jorge Zahar, 1997.

LASTRES, H. M. M.; FERRAZ, J. C. Economia da informação, do conhecimento e do aprendizado. In: LASTRES, H. M. M.; ALBAGLI, S. Informação e globalização na era do conhecimento. Rio de Janeiro: Campus, 1999. p. 27-57.

LE COADIC, Y.. A ciência da informação. 2. ed., rev. atual. Brasília: Briquet de Lemos, 2004.

LE GOFF, J. História e memória. 4 ed. Campinas: Editora da UNICAMP, 2003.

LIMA, M. G.; MIRANDA, M. O.; VILDEANE, B. da R. A memória e os sistemas memoriais. In: ENCONTRO NACIONAL DE PESQUISA EM CIÊNCIA DA INFORMAÇÃO, 12., 2011, Brasília. Anais...Brasília: UnB, 2011. p. 3328-3339.

MARINHO JUNIOR, I. B.; SILVA, J. G. da C. G. e. Arquivos e informação: uma parceria promissora. Arquivo \& Administração, Rio de Janeiro, v. 1, n. 1, p. 15 - 32, jan./jun. 1998.

MENESES. U. T. B. de. A crise da memória histórica e documentos: reflexões para um tempo de transformações. In: SILVA, Z. L. (Org.). Arquivos, patrimônio e memória: trajetória e perspectivas. São Paulo: UNESP; FAPESP, 1999. (Seminários \& Debates)
MORIGI, V. J. et al. Competência informacional e cidadania no contexto brasileiro: o bibliotecário como agente mediador. Disponível em: $<$ http:/ / competenciainformacional.files.wordp ress.com/2013/03/enancib-2012i.pdf>. Acesso em: 08 jul 2013.

MURGUIA, E. I. A memória e sua relação com arquivos, bibliotecas e museus. In:

(Org.). Memória: um lugar de diálogo para arquivos, biblioteca e museus. São Carlos: Compacta Gráfica e Editora. 2010. p. 11-32.

NORA, P. Entre memória e história: a problemática dos lugares. Projeto História. São Paulo, n. 10, p. 07-28, dez. 1993.

OLIVEIRA, E. B. O Conceito de memória na Ciência da Informação: análise das teses e dissertações dos programas de pós-graduação. 2010. 196f. Tese (Doutorado em Ciência da Informação) - Universidade Nacional de Brasília, 2010. Disponível em: < http://repositorio.bce.unb.br/bitstream/1048 2/7466/1/2010_ElianeBragaOliveira.pdf >. Acesso em: 25 mar. 2011.

; RODRIGUES, G. M. O Conceito de memória na Ciência da Informação: análise das teses e dissertações dos programas de pósgraduação. In: MARIZ, A. C. A.; JARDIM, J. M.; SILVA, S. C. de A. (Orgs.). Novas dimensões da pesquisa e do ensino da Arquivologia no Brasil. Rio de Janeiro: Móbile, 2012. p. 495-511

POLLAK, M. Memória e identidade social. Estudos Históricos, Rio de Janeiro, vol. 5, n. 10, 1992, p. 200-212 (1-15).

Memória, esquecimento silêncio.

Estudos Históricos, Rio de Janeiro, vol. 2, n. 3, p 3-15, 1989

SHERA, J. H. The foundations of education for librarianship. New York : Becker and Hayes, 1972.

SILVA, V. F. da. Migrantes na periferia urbana: redes sociais e a construção do bairro. 
[on-line]. Revista do núcleo de antropologia urbana da USP, ano 1, versão 1.0, julho, 2007. NAU - Núcleo de Antropologia Urbana. Disponível em: http:/ /www.n-au.org/pontuurbe02/goncalves2008.html>.

Acesso em: 15 jul. 2013.
SIQUEIRA, I. C. P. Pressupostos para um programa nacional de competências informacionais. Ciência da Informação, Brasília, v. 40 n. 3, p.478-491, set./dez. 2011. 